\title{
Fault Identification of LCC HVDC Using Signal Processing Techniques
}

\author{
Benish Paily \\ Technological University Dublin \\ Malabika Basu \\ Technological University Dublin, mbasu@tudublin.ie \\ Michael Conlon \\ Technological University Dublin, michael.conlon@tudublin.ie
}

Follow this and additional works at: https://arrow.tudublin.ie/engscheleart

Part of the Electrical and Computer Engineering Commons

\section{Recommended Citation}

Paily, B.; Basu, M.; Conlon, M., "Fault identification of LCC HVDC using signal processing techniques," Power Engineering Conference (UPEC), 2013 48th International Universities', vol., no., pp.1,6, 2-5 Sept. 2013 doi: 10.1109/UPEC.2013.6715019

This Conference Paper is brought to you for free and open access by the School of Electrical and Electronic Engineering at ARROW@TU Dublin. It has been accepted for inclusion in Conference papers by an authorized administrator of ARROW@TU Dublin. For more information, please contact arrow.admin@tudublin.ie, aisling.coyne@tudublin.ie,gerard.connolly@tudublin.ie.

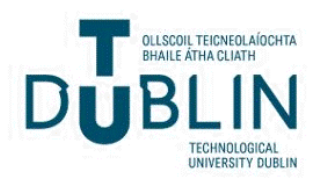




\section{Fault Identification of LCC HVDC using Signal Processing Techniques}

\author{
Benish Paily \\ School of Electrical and \\ Electronic Engineering \\ Dublin Institute of Technology \\ E-mail:benishkp@yahoo.com
}

\author{
Malabika Basu \\ School of Electrical and \\ Electronic Engineering \\ Dublin Institute of Technology \\ E-mail: mbasu@,ieee.org
}

\author{
Michael Conlon \\ School of Electrical and \\ Electronic Engineering \\ Dublin Institute of Technology \\ E-mail: michael.conlon@dit.ie
}

\begin{abstract}
Line commutated HVDC (LCC HVDC) technology has been in operation with a high level reliability and little maintenance requirements for more than 30 years. This technology plays an important role in particular in the wind energy industry. The current-source based or classical LCCHVDC systems are being considered for buried cable transmission as well as overhead transmission. The fault analysis and protection of LCC-HVDC system is a very important aspect in terms of power system stability. This paper presents a comparative study of $a b c$ to $d q 0$ transformation, and wavelet transform-based analysis for the identification of faults in an LCC HVDC system.
\end{abstract}

Index Terms-abc to dq0 transform, fault analysis, fault detection, LCC HVDC, Matlab/Simulink, wavelet transform.

\section{INTRODUCTION}

HVDC transmission is expected to be used to transmit electricity generated from renewable power plants to urban areas. The global power transmission market (including HVDC) will amount to $€ 5-9$ billion per year in the next five years. The HVDC transmission market is expected to double within the next five years from a current $€ 3$ billion per year. Thus the demand for HVDC transmission is increasing rapidly. In the last 40 years, HVDC transmission links with a total capacity of $100 \mathrm{GW}$ (equivalent to the capacity of 100 large power plants) were installed. Another $250 \mathrm{GW}$ will be added in this decade alone [1].

HVDC transmission can be based on two alternative technologies: Voltage Source Converter (VSC) using IGBTs and Line Commutated Converter (LCC) using thyristors. The LCC HVDC is a quite mature technology and it has been in operation for more than 30 years with little maintenance [2]. LCC technology is still being developed with the protection of the system attracting particular attention. The detection and fast clearance of faults are important for safe and optimal operation of power systems. Due to the integration of fast acting HVDC systems in ac power systems, it is necessary to detect, classify and clear the faults as fast as possible [3]. Fault identification in HVDC systems is a challenging process as it may not be possible to identify HVDC faults using pure frequency or time domain based methods [4-5]. The general faults that can occur in LCC HVDC are a) ac side faults b) dc side faults. The other faults which can appear in
HVDC are (1) Converter station faults such as arc through, arc back and misfire (2) Commutation failure (3) Short circuits inside the converter units. In the case of current source converter HVDC, a fault on the ac side can lead to commutation failures which results in a collapse of the dc line voltage. Therefore, this technology is vulnerable to ac side faults. Moreover, current source converters require relatively strong ac sources and consume reactive power at every terminal location. To give better protection, the identification of the fault is very important. This paper discussed two different methods which are based on signal processing techniques to identify the faults accurately. The methods are discussed below.

\section{A. ABC to DQ0 transformation}

The abc to dq0 transformations computes the direct axis, quadratic axis, and zero sequence quantities in a two-axis rotating reference frame for a three-phase sinusoidal signal. By using this transformation, the balanced three phase signal quantities are converting to two dc quantities. The following transformation is used:

$$
\begin{aligned}
& V_{d}=2 / 3\left[V_{a} \sin \omega t+V_{b} \sin \left(\omega t-\frac{2 \pi}{3}\right)+V_{c} \sin \left(\omega t+\frac{2 \pi}{3}\right)\right] \\
& V_{q}=2 / 3\left[V_{a} \cos \omega t+V_{b} \cos \left(\omega t-\frac{2 \pi}{3}\right)+V_{c} \cos \left(\omega t+\frac{2 \pi}{3}\right)\right] \\
& V_{0}=1 / 3\left[V_{a}+V_{b}+V_{c}\right]
\end{aligned}
$$

This transformation is commonly used in three phase electrical machine models, where it is known as the Park transformation [6]. This transformation is applied into the fault analysis of a LCC HVDC system and shows how it is effective in detecting variations in the transformed quantities.

\section{B. Wavelet transformation}

The wavelet transform has the capability of analysing signals simultaneously in both the time and frequency domains. The wavelet transform is the mathematical theory 
associated with building a model for non-stationary signals using a family of wavelets. Wavelet analysis is the breaking up of a signal into shifted and scaled versions of the original (or mother) wavelet. Moreover, it can adjust analysis windows automatically according to frequency, namely, shorter windows for higher frequency and vice versa. A wavelet is a function $\psi$ with a zero average value

$$
\int_{-\infty}^{+\infty} \varphi(t) d t=0
$$

The wavelet expansion set is not unique. There are many different wavelets systems that can be used effectively, but all seem to have the following three general characteristics [7-8].

1. A wavelet system is a set of building blocks to construct or represent a signal or function.

2. The wavelet expansion gives a time-frequency localization of the signal.

3. The calculation of the coefficients from the signal can be done efficiently.

Some of the common wavelets used in the power system studies are Meyer wavelet, Daubechies wavelet, Morlet wavelet and Mexican Hat wavelet. The purpose of this paper is to show how to detect exact transients of signal changes by using db4 wavelets.

\section{SIMULATION MODEL}

A standard model of a LCC HVDC system has been simulated in the SIMULINK platform under the MATLAB environment. Fig. 1 shows the simulation model in which a $1000 \mathrm{MW}(500 \mathrm{kV}, 2 \mathrm{kA}) \mathrm{dc}$ line is used to transmit power from a $500 \mathrm{kV}, 5000 \mathrm{MVA}$, and $60 \mathrm{~Hz}$ system to a $345 \mathrm{kV}$, $10000 \mathrm{MVA}$, and $50 \mathrm{~Hz}$ system. The dc line is $300 \mathrm{~km}$ long and the ac systems are represented by damped L-R equivalents. DC faults are initiated from 0.7 to 0.75 seconds at various locations and ac faults are initiated from 0.7 to 0.8 seconds. The analysis is simulated for various faults such as dc faults at various locations and ac faults such as single line to ground fault (SLG), line to line fault (LL), double line to ground fault (DLG), and triple line (3L) fault at the side of rectifier of the system. The fault currents are analysed through two techniques identified above.

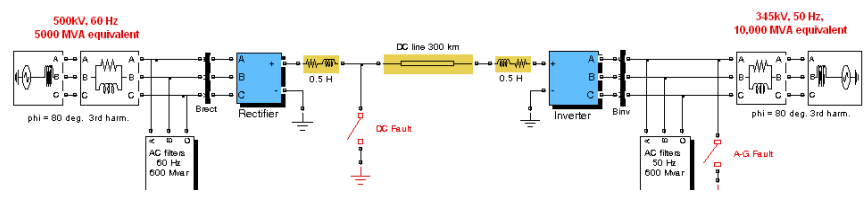

Fig. 1. Simulation model of HVDC transmission system

\section{RESULTS AND DISCUSSIONS}

\section{A. abc to $d q 0$ analysis}

In this abc to dq0 analysis of the LCC system, three conditions can be considered which are normal operation, $\mathrm{dc}$ faults at various locations and different ac faults on the rectifier (or inverter) side.

For the purpose of analysis, only dc faults are applied at $50 \mathrm{~km}, 100 \mathrm{~km}, 150 \mathrm{~km}, 200 \mathrm{~km}$ and $250 \mathrm{~km}$ with fault resistance $0.001 \Omega$. Whenever the fault is applied the input $\mathrm{AC}$ waveform of the rectifier is also affected which shows up in the current waveshapes. These can be detected by using the $\mathrm{dq} 0$ transformation of the current. From the experiment it is observed that the dq0 transformation will have significant effect on the values of the currents. The three phase base power of the system is $100 \mathrm{MVA}$ and base voltage is $500 \mathrm{kV}$ phase to phase. The system current shows in per unit/100MVA. In the normal case there is no dc fault in the system. For this condition the peak magnitude of the dq value is 12.38. To obtain the magnitude of dq of a set of three-phase voltage or current following equation (3) can be used.

$$
\begin{gathered}
\text { Magnitude of } d q=\sqrt{V q^{2}+V d^{2}} \\
\text { Magnitude of } d q=\sqrt{I q^{2}+I d^{2}}
\end{gathered}
$$

where $V_{d}\left(I_{d}\right)$ or $V_{q}\left(I_{q}\right)$ can be derived from (1). In the second case, a dc fault at $50 \mathrm{~km}$ from the rectifier side is initiated from 0.7 to 0.75 second. The input ac waveform of the rectifier is affected which can be seen in Fig. 2(a). The peak magnitude of dq is 26.58 (approximately) and variations can be seen in Fig. 2(b). From the normal conditions, the peak magnitude is varied from 12.38 to 26.58 in unit value. The next case is a dc fault at $250 \mathrm{~km}$ which is initiated from 0.7 to 0.75 second from the rectifier side. The detection of the parameters is shown in Fig. 2(c). The peak value changes to 28.40 from its normal value. 


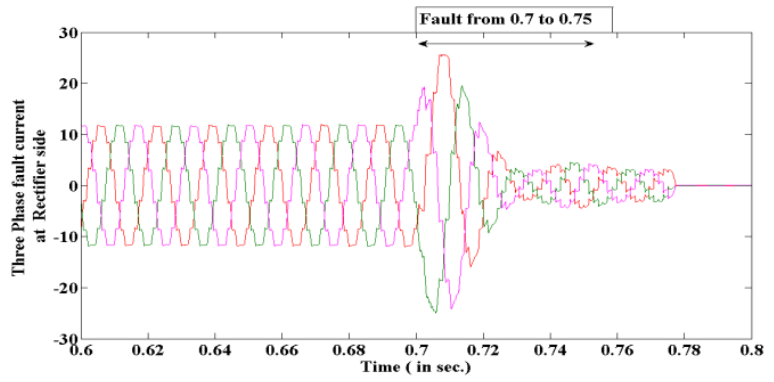

(a)

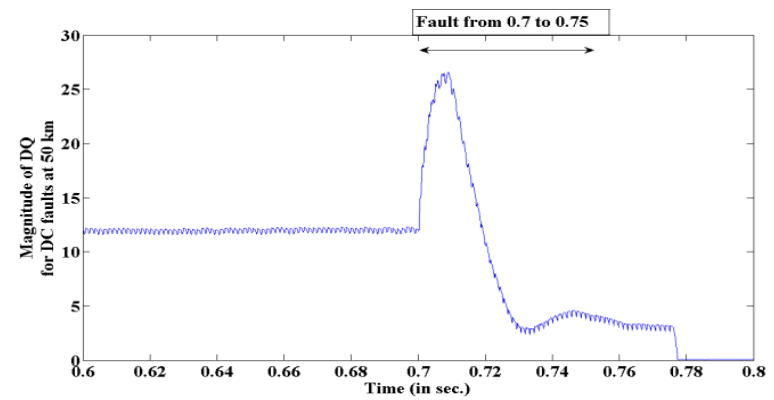

(b)

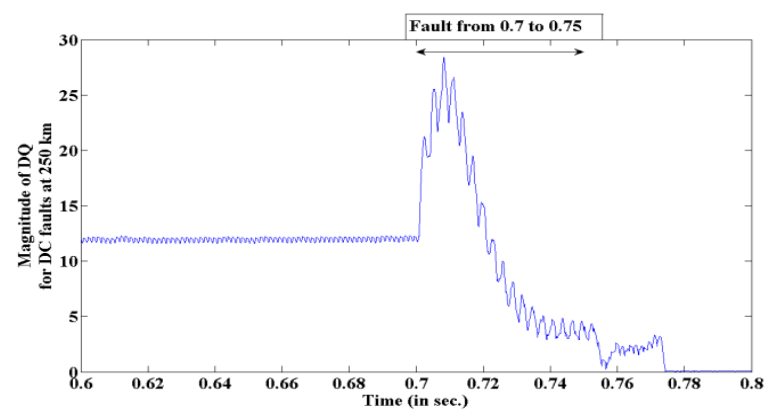

(c)

Fig. 2. Detection of dq0 transformation for dc fault at $50 \mathrm{~km}, 250 \mathrm{~km}$ from rectifier side

Table I shows the peak magnitude of the dq for a de fault at $50 \mathrm{~km}, 100 \mathrm{~km}, 150 \mathrm{~km}, 200 \mathrm{~km}, 250 \mathrm{~km}$. DQ values changing to greater than 26 are indicative of a fault, but the accurate determination of the distance to the fault cannot be made with this method alone.

TABLE I

PEAK MAGNITUde OF DQ UNDER DC FAULTS

\begin{tabular}{|l|c|c|}
\hline Parameter & Distance $(\mathrm{km})$ & DQ magnitude \\
\hline Normal Operation & 0 & 12.38 \\
\hline \multirow{4}{*}{ DC Fault } & 50 & 26.58 \\
\cline { 2 - 3 } & 100 & 27.48 \\
\cline { 2 - 3 } & 150 & 28.09 \\
\cline { 2 - 3 } & 200 & 28.18 \\
\cline { 2 - 3 } & 250 & 28.40 \\
\hline
\end{tabular}

\section{B. HVDC system subjected to ac faults}

In this section only ac faults at the rectifier are considered. The single line to ground fault (SLG), line to line fault (LL fault), double line to ground fault (DLG fault) and triple line (3L) fault are analysed. Whenever the ac fault is initiated, the ac line currents are changed. These variations can be detected by using dq0 transformation. Here, only three cases are reported for the purpose of explanation.

1) Normal condition of the system

2) Single line to ground fault (SLG) at rectifier side

3) Double line to ground fault (DLG) at rectifier side

In the normal case where there is no fault in the system, the actual input current passes through the $\mathrm{dq} 0$ transformation which is equal to 12.38 unit magnitude of current. In the second case when the single line to ground (SLG) fault is initiated at 0.7 to 0.8 second at the rectifier, the magnitude of the input ac current is increased from the normal value 12.38 unit to peak value 99.23 unit. This is shown in Fig. 3(a). In the third case when the double line to ground faults (DLG) is applied, the input current is increased from 12.38 unit to 144.95 unit which is shown in Fig. 3(b).

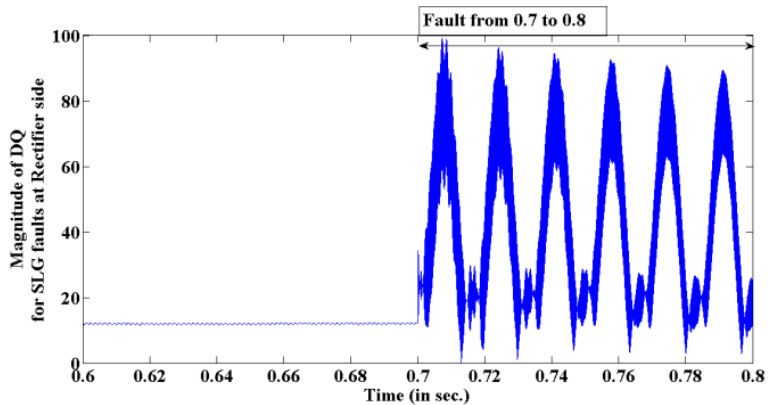

(a)

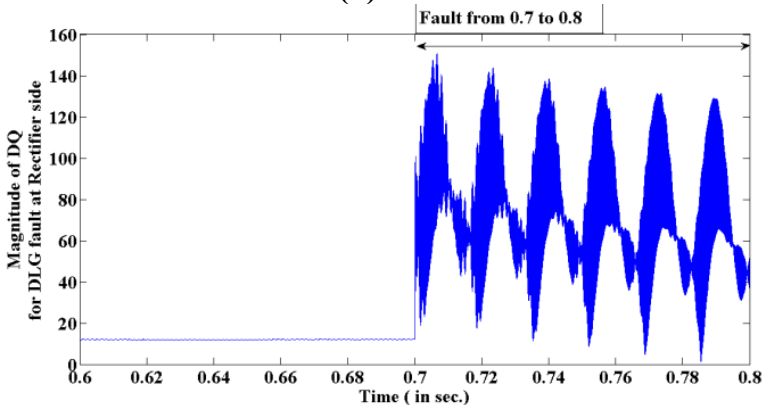

(b)

Fig. 3. Identification of SLG and DLG faults through dq0 transformation

For the remaining two analyses, with the line to line fault the peak magnitude is increased from the normal value to 150.6 and for triple line to ground fault the peak magnitude is increased from the normal value to 223.18. The analysis shows that there is a significant change in the values of the 
dq0 transform parameters when the system is under the fault condition. Here, dq values changing to greater than 99 will be indicative of an ac side fault. The ac current values of the rectifier are used in this analysis as the input of the dq0 transformation and the fault resistance is $0.001 \Omega$. The peak magnitude of the current for various ac faults in terms of $\mathrm{dq}$ transformation is expressed in Table II below.

TABLE II

PeAK Magnitude of DQ VALUeS UNDER AC FAULTS AT ReCTIFIER SIDE

\begin{tabular}{|l|l|}
\hline AC Faults at Rectifier side & $\begin{array}{l}\text { Peak Magnitude of dq in } \\
\text { unit }\end{array}$ \\
\hline No Fault & 12.38 \\
\hline Single line to ground fault & 99.23 \\
\hline Line to line fault & 150.60 \\
\hline Double line to ground fault & 144.96 \\
\hline Triple line to ground fault & 223.18 \\
\hline
\end{tabular}

\section{Wavelet analysis in HVDC system}

Transient signals in dynamic systems may undergo abrupt changes such as a jump, or a sharp change in the first or second derivatives. Fourier analysis usually cannot detect those events. The purpose of the following simulation is to show how analysis by wavelets can detect the exact instant when a signal changes by virtue of changes in the amplitude of the wavelet coefficients in various levels. In wavelet analysis, the approximation coefficient (cA) is the high-scale, low frequency components of the signal. The details coefficient (cD) is the low-scale, high frequency components. For the analysis of decomposition of signals, discrete wavelet $\mathrm{db} 4$ is used as a mother wavelet and $5^{\text {th }}$ level wavelet coefficients are plotted which clearly shows whether the line is under fault or not. In the experiment, detailed analysis has been done and here two cases are considered.

1) $\mathrm{DC}$ fault at $50 \mathrm{~km}$ from rectifier side

2) $\mathrm{DC}$ fault at $150 \mathrm{~km}$ from rectifier side

Under normal condition the actual dc link current is considered as the input of the wavelet transform. After the processing it is observed that the variations of the wavelet coefficients from level one to level five are more or less the same. Even if the power varies from 50 to $100 \%$ the changes of the coefficients is not very significant. The absolute value of dc current coefficients variation is in between 0.06 to 0.09 when the system is under normal operation. In the first case, a $\mathrm{dc}$ fault is initiated at $50 \mathrm{~km}$ away from rectifier side. The fault time is from 0.7 to 0.75 second. Under this condition the variation of the actual dc line current is shown in Fig. 4(a). After the processing by wavelet transform in five levels the absolute maximum value of the dc current coefficients is 0.18 . The $5^{\text {th }}$ level wavelet coefficients plot can be seen in
Fig. 4(b). From this analysis it is clear the coefficients value varies from 0.09 to 0.18 which is clearly discriminated from normal operating condition. In the second case a dc side fault is initiated at $150 \mathrm{~km}$ away from the rectifier side. The fault time is the same as before. When the system experiences this fault the variation of actual dc line current is shown in Fig. 4(c). This dc line current is processed by the wavelet transform and it is observed that the absolute maximum value of the dc current coefficients is 0.67 . The corresponding $5^{\text {th }}$ level coefficients plot can be seen in Fig. 4(d). From this analysis it is observed that the variation from the normal value of the coefficients is varied from 0.09 to absolute maximum value of 0.67 .

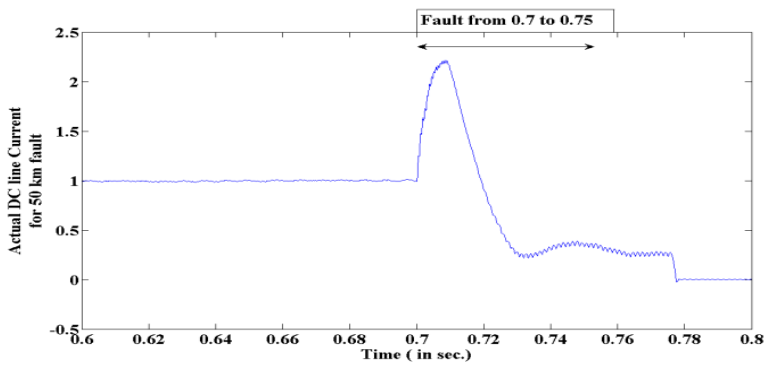

(a)

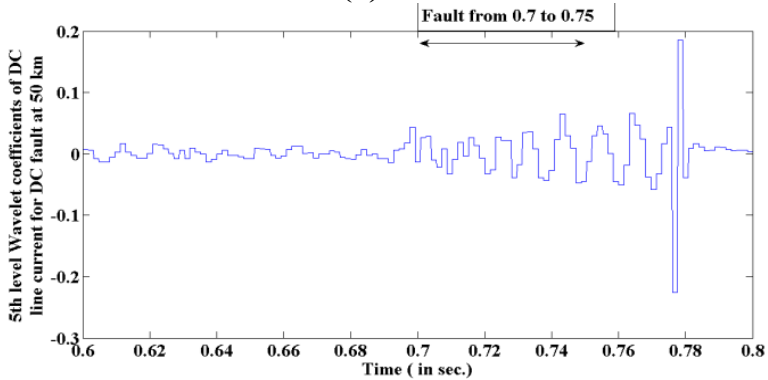

(b)

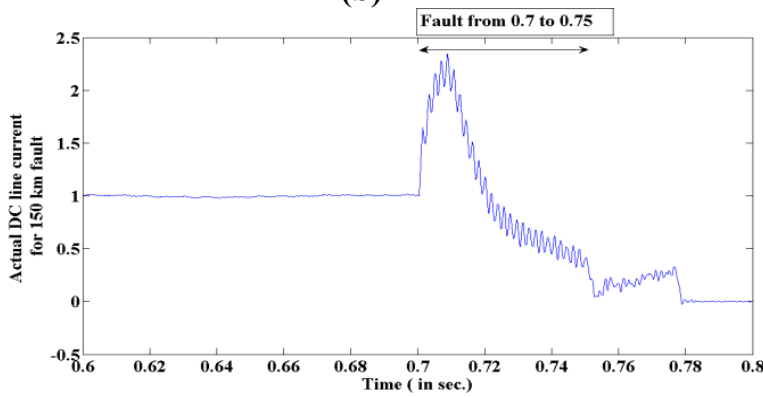

(c)

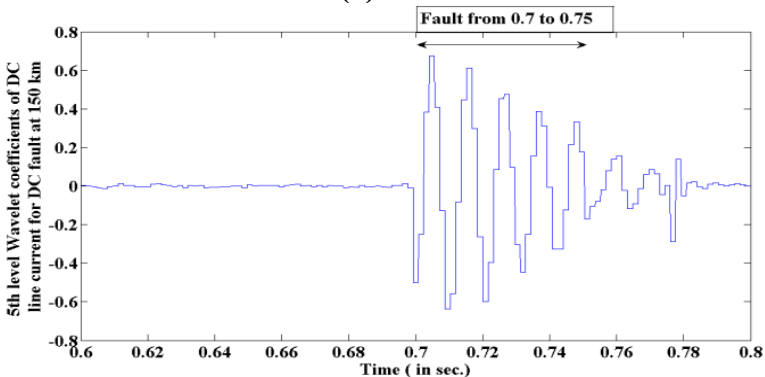

(d)

Fig. 4. $5^{\text {th }}$ level wavelet coefficients of dc current when system is subjected to dc faults at $50 \mathrm{~km}, 150 \mathrm{~km}$ from rectifier side 
Table III shows the absolute maximum value of the dc current wavelet coefficients in five levels. From this table it can be seen when the system experienced a fault at $100 \mathrm{~km}$ the maximum coefficients is 0.28 and when a dc fault is applied at $200 \mathrm{~km}$, the wavelet maximum coefficients is 0.78 . In the case of a fault at $250 \mathrm{~km}$, the maximum value is 0.83 . In the analysis it is observed that the wavelet transform has a capability to detect the distance of fault location in the system, but that is required to be correlated.

TABLE III

ABSOLUte MAXIMUM VALUE OF THE WAVELET COEFFICIENTS OF THE DC LINE CURRENT

Absolute maximum value of five levels wavelet coefficients of dc line current for dc fault at various fault distances

\begin{tabular}{|l|l|l|l|l|l|l|}
\hline DC Fault & $\begin{array}{l}\text { Normal } \\
\text { Operation }\end{array}$ & $\begin{array}{l}50 \\
\mathrm{~km}\end{array}$ & $\begin{array}{l}100 \\
\mathrm{~km}\end{array}$ & $\begin{array}{l}150 \\
\mathrm{~km}\end{array}$ & $\begin{array}{l}200 \\
\mathrm{~km}\end{array}$ & $\begin{array}{l}250 \\
\mathrm{~km}\end{array}$ \\
\hline $\begin{array}{l}\text { Max. } \\
\text { value of } \\
\text { wavelet } \\
\text { coefficie } \\
\text { nts in } \\
\text { five level }\end{array}$ & 0.09 & 0.18 & 0.28 & 0.67 & 0.78 & 0.83 \\
& & & & & & \\
\hline
\end{tabular}

\section{Wavelet transform in ac fault analysis}

In this analysis, HVDC system experiences symmetrical and unsymmetrical faults like single line to ground (SLG), line to line (LL), double line to ground (DLG) and triple line fault (LLL). The following cases are considered.

\section{1) Single line to ground fault at rectifier side \\ 2) Line to line fault at rectifier side}

In the case of a single line to ground (SLG) fault which appears between 0.7 to 0.8 second, the actual dc line current is shown in Fig. 5(a). The corresponding wavelet coefficients of the dc line current in $5^{\text {th }}$ level can be seen in Fig. 5(b). The maximum coefficients value is around 0.35 and it is clearly discriminated from the normal value 0.09 . In the second case a line to line fault is initiated at 0.7 to 0.8 second. Fig. 5(c) shows that the actual dc line current under this condition. The corresponding $5^{\text {th }}$ level absolute maximum value of dc line current coefficients is plotted in Fig. 5(d). From this analysis it is observed that the coefficient varies from the normal value of 0.09 to the maximum value of 0.43 .

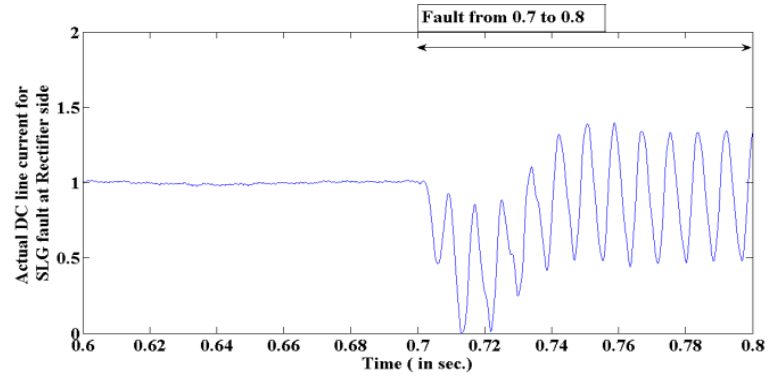

(a)

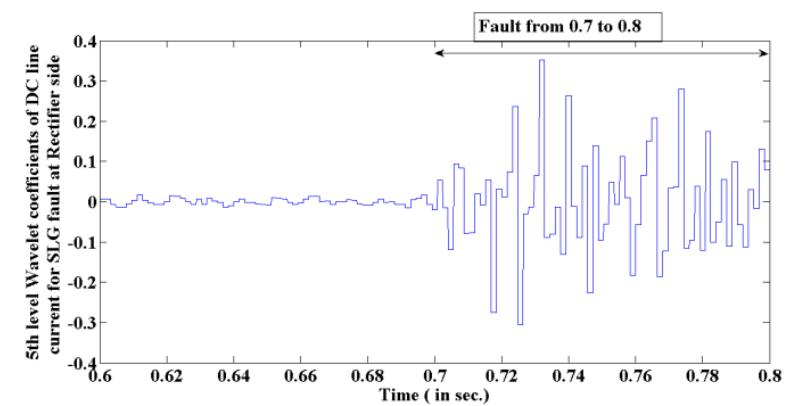

(b)

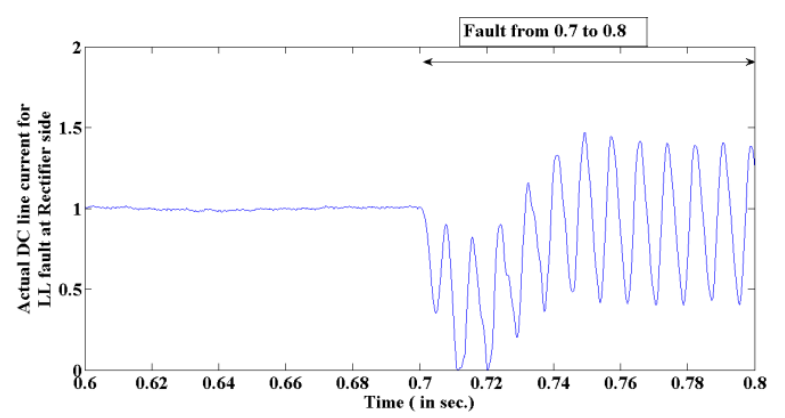

(c)

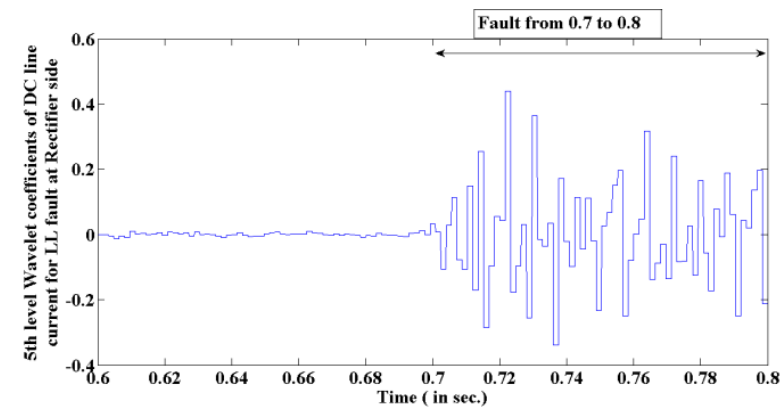

(d)

Fig. 5. $5^{\text {th }}$ level wavelet coefficients of dc line current when the system is subjected to SLG, and LL fault at the rectifier side

Table IV shows the absolute value of the $5^{\text {th }}$ level wavelet coefficients of the dc line current for various ac faults at the side of the rectifier. In the case of a double line to ground fault the maximum value is 0.25 and in a triple line (LLL) to ground fault, the maximum value is 0.41 . 
TABLE IV

ABSOLUTE MAXIMUM VALUE OF THE WAVELET COEFFICIENTS OF THE DC LINE CURRENT FOR AC FAULT CONDITIONS

Absolute maximum value of five levels wavelet coefficients of dc current for various ac fault at rectifier side

\begin{tabular}{|l|l|l|l|l|l|}
\hline $\begin{array}{l}\text { AC Fault at } \\
\text { Rectifier } \\
\text { side }\end{array}$ & $\begin{array}{l}\text { Normal } \\
\text { Operation }\end{array}$ & SLG & LL & DLG & LLL \\
\hline $\begin{array}{l}\text { Maximum } \\
\text { coefficients }\end{array}$ & 0.09 & 0.35 & 0.43 & 0.25 & 0.41 \\
\hline
\end{tabular}

\section{CONCLUSION}

Fault identification in HVDC systems is a challenging process because it should be accurate and fast. This paper tries to show the importance of abc to dq0 transformation and wavelet transformation in the fault analysis of HVDC systems. Both techniques can be applied to fault identification. In fault identification, the abc to dq0 transform performed very well but the accuracy of fault distance estimation was poor. The wavelet transform is considered as a powerful signal processing technique for transient analysis of signal. Wavelet transformation effectively proved that it can detect the abrupt changes of the signal indicative of a fault. This paper considers dc faults at various distances and ac faults on the rectifier side. These coefficients can be used to discriminate the various faults in the LCC HVDC system.

\section{REFERENCES}

[1] http://www.energy.siemens.com/hq/en/power-transmission/hvdc/, available online on $6^{\text {th }}$ June, 2013.

[2] K.R.Padiyar, "HVDC Power Transmission Systems", New Age International (P) Limited, Publishers, New Delhi, $2^{\text {nd }}$ ed., 2010.

[3] Rashmi A.Keswani, "Identification of Fault in HVDC Converters using Wavelet Based Multi-Resolution Analysis", First International Conference on Emerging Trends in Engineering and Technology, IEEE, pp.954-959, 2008.

[4] L.Tang, B.T.Ooi, "Protection of VSC multi terminal HVDC against DC faults", $33^{\text {rd }}$ Annual IEEE Power Electronics Specialist Conference, vol.2, pp.719-724,Nov.2002.

[5] L.Tang, B.T.Ooi, "Locating and Isolating DC faults in multi terminal DC systems", IEEE Trans. On Power Delivery, vol.22, no.3, pp.18771884, July 2007.

[6] Paul C.Krause, Oleg Wasynczuk, Scott D. Sudhoff, "Analysis of Electric Machinery"; IEEE Power Engineering Society, IEEE Press, $5^{\text {th }}$ March, 2002.

[7] C. Sidney B, R.A Gopinath, H.Guo, "Introduction to Wavelets and Wavelet Transforms" Prentice Hall, New Jersey, 1998.

[8] M.Basu, B.Basu, "Application of Wavelet Transform for Power Quality (PQ) Disturbance Analysis", Second International Conference PEMD, vol.1, pp. 269-273, 2004. 